\title{
Thermal Performance and Viscosity of Biologically Produced Silver/Coconut Oil Nanofluids
}

\author{
M. M. Sarafraz, ${ }^{\text {a,* }}$ A. Arya, ${ }^{\text {b }}$ V. Nikkhah, ${ }^{\text {a }}$ and F. Hormozi ${ }^{a}$ \\ ${ }^{a}$ Faculty of Chemical, Petroleum and Gas Engineering, \\ Semnan University, Semnan, Iran \\ ${ }^{\mathrm{b}}$ School of Engineering and Technology, \\ Purdue University, IUPUI, Indianapolis, USA
}

doi: 10.15255/CABEQ.2015.2203

Original scientific paper

Received: March 16, 2015

Accepted: December 14, 2016

In this work, thermal conductivity, viscosity, and boiling heat transfer coefficient of a biologically produced nano-coolant were experimentally quantified. The nanoparticles were produced from silver nitrate via the plant extraction method and by means of green tea leaf extract. The mean size of the particles was $50 \mathrm{~nm}$, with spherical morphology and single-phase structure of Ag (silver). The synthesized particles were dispersed in coconut oil as base fluid. Thermal conductivity and viscosity of the nanofluid were experimentally measured and correlated based on temperature and concentration of nanoparticles via the regression analysis. Thermal performance of the nanofluid inside an annular heat exchanger with convective boiling conditions (in forced convection and nucleate boiling heat transfer regimes) was assessed. The results demonstrated a superior thermal performance in both heat transfer regions over the base oil, and revealed that this nanofluid can be used as a coolant as well as a lubricant in engines with high heat flux conditions, as its thermal conductivity and viscosity were enhanced due to the presence of Ag particles inside the oil.

Key words:

silver nanoparticle, thermal conductivity, viscosity, boiling heat transfer, plant extraction

\section{Introduction}

Continuous progress in designing a new generation of powerful car engines has led to the enhancement of the heat transfer rate in engine cooling systems, which has faced the designers with serious limitations for cooling the engines. Subsequently, demands for highly efficient cooling systems have increased. Traditional working fluids such as water and engine oils are commonly used in many industrial sectors including power cycles, automotive industries or lubricating processes. The major challenge of using traditional coolant is that the thermal properties of these coolants are relatively poor ${ }^{1}$. For example, thermal conductivity of water is $0.65 \mathrm{~W} \mathrm{~m}^{-1} \mathrm{~K}^{-1}$, while it is $120 \mathrm{~W} \mathrm{~m}^{-1} \mathrm{~K}^{-1}$ for copper oxide. To address the mentioned challenge, nanofluids have been introduced as a promising way to enhance the thermal properties of coolants. These fluids are dilute colloidal suspensions of solid nanoparticles (with mean average size of 1-100 $\mathrm{nm}$ ), which have been dispersed in a base liquid (e.g. water or oil). A very small amount of nanoparticles can provide dramatic improvements in thermal properties of a base fluid $^{2-9}$.

*Corresponding author: Email: mohamadmohsensarafraz@gmail.com; Tel: +989120976870; Fax: +989214774016
Boiling heat transfer is a highly efficient process of heat dissipation with a span of application in thermal engineering. Much effort has been made to investigate the thermal performance of different nanofluids on pool, flow and film boiling heat transfer coefficient ${ }^{10-18}$. In most previous works regarding nanofluids, it has been found that thermal conductivity of nanofluids is higher than that reported for the base fluid. However, thermal performance of the nanofluids in boiling systems is yet to be completely understood. For instance, in an experimental work conducted by Fan et al. ${ }^{13}$, stainless steel spheres in dilute aqueous graphene oxide nano-sheets nanofluids at various concentrations (by weight) up to $0.1 \mathrm{wt}$ \% $\%$ were quenched. The experiments were performed for saturated boiling, and boiling curves were obtained for the nanofluids in comparison to the baseline case of pure water. It was shown that quenching is accelerated upon increasing the concentration of nanofluids. The enhanced boiling heat transfer by the nanofluids was interpreted in relation to the modified surface properties, including morphology, wettability, and roughness, on the quenched surfaces. However, as the nanofluids were water based, they could be used in high heat flux systems. Moreover, the authors reported no visual investigations on the deposition and fouling formation of particles on the heating surface. 
Sarafraz et al. ${ }^{14-16}$ established experiments on thermal performance of alumina and copper oxide nanofluids in a boiling pool. They demonstrated that pool boiling heat transfer can be deteriorated over extended time, since nanoparticles can form a fouling layer on the surface, which causes a significant thermal resistance. Tang et al. ${ }^{17}$ performed a set of experiments on pool boiling heat transfer characteristics of gamma alumina/R141b nanofluids on a horizontal flat square copper surface at heat fluxes in the range $10-200 \mathrm{~kW} \mathrm{~m}^{-2}$. The surface roughness has been controlled by sandpaper of grade \#2000 before boiling. The results show that the presence of alumina nanoparticles can enhance or deteriorate the pool boiling heat transfer coefficient, which strongly depends on the concentration of nanoparticles dispersed in the base fluid.

In another study, nucleate boiling heat transfer of alumina-water-ethylene glycol nanofluids under atmospheric pressure was investigated by Raveshi et al. ${ }^{18} \mathrm{He}$ and his co-workers evaluated six different volume fractions of the nanofluids to study the impact of concentration on boiling heat transfer of binary mixture of water/ethylene glycol based nanofluids. The results showed the high effectiveness of the nanoparticles on the heat transfer coefficient. In addition, the experimental results indicated that there is an optimum volume concentration of nanoparticles, in which the heat transfer coefficient has its maximum value. Furthermore, the optimum volume concentration of nanoparticles and the maximum increment of boiling heat transfer coefficient in their study were $0.75 \%$ and $64 \%$, respectively. Although they reported a slight enhancement in thermal performance of the system, they mentioned no information regarding the sedimentation and status of particles over the extended period of operation. As mentioned, water/ethylene glycol is not an appropriate coolant for high heat flux conditions. To address this challenge, oil-based nanofluids are a promising option for high heat flux systems. Much efforts have been made to investigate the effect of the presence of particles in oils. A summary of these researches is presented in Table 1.

According to Table 1, nanoparticles have a significant role in thermal performance and viscosity of oil-based nanofluids. Nanoparticles can be produced using green synthesis via plant extracts. Much effort has been made to obtain biologically produced nanoparticles from plant extraction method. For instance, in a study conducted by Wang et $a l .{ }^{28}, \mathrm{AgNPs}$ were synthesized using the cell filtrate

Table 1 - Investigations on the influence of the presence of particles in oils and on thermal performance of the systems

\begin{tabular}{|c|c|c|}
\hline Author & Nanofluid & Remarks \\
\hline Behabadi et al. ${ }^{19}$ & $\mathrm{CuO}$-synthesized oil & $\begin{array}{l}\text { vol. } \%=0.5-1.5 \text {, Laminar regime, heat exchanger with micro-fin tubes, heat transfer } \\
\text { enhancement up to } 230 \% \text {, no stability analysis, maximum pressure drop } 42-47 \%\end{array}$ \\
\hline Shi et al. ${ }^{20}$ & $\mathrm{Cu}$-oil & $\begin{array}{l}\text { vol. } \%=0.001-0.2 \text {, Preparation of nanofluid was carried out by Two-step method. } \\
\text { Thermal conductivity was measured using hot wire method, thermal properties were } \\
\text { enhanced due to the base fluid and intensified because of the nanoparticles, maximum } \\
\text { enhancement was } 18 \% \text { for vol. } \%=0.2\end{array}$ \\
\hline Hemalatha et $a .^{21}$ & ZnO-coconut oil & $\begin{array}{l}\text { vol. } \%=0-2.5 \% \text {, Ultrasonically Two-step method was employed to prepare the nano- } \\
\text { fluids, experimental viscosity was measured and correlation was proposed. Shear thin- } \\
\text { ning behavior was reported. No information on thermal conductivity. }\end{array}$ \\
\hline Behabadi et al. ${ }^{22}$ & CuO-base oil & $\begin{array}{l}\text { wt. } \%=0.2-2 \text {, laminar flow, all thermal properties were experimentally measured, } \\
\text { heat transfer enhancement }=12.8 \% \text {, Newtonian behavior is reported for the coolant, } \\
\text { no information on stability of nanofluids are reported. }\end{array}$ \\
\hline Xie et $a .^{23}$ & $\begin{array}{l}\text { MWCNT-silicon } \\
\text { based oil }\end{array}$ & $\begin{array}{l}\text { CNT fraction not mentioned. Multi-walled carbon nanotube was produced using } \\
\text { mechano-chemical method, functionalized and dispersed in silicon based oil, potential } \\
\text { thermal application for nanofluids is reported by measuring the rheological properties. }\end{array}$ \\
\hline Ashtiani et al. ${ }^{24}$ & MWCNT-oil & $\begin{array}{l}\text { vol. } \%=0.002,0.005,0.01 \text {, at fully-developed regime and constant wall temperature } \\
\text { condition, heat transfer enhancement is reported. No specific values of enhancement } \\
\text { are given. Better thermal properties were seen for oil based nanofluids rather than } \\
\text { base fluids. }\end{array}$ \\
\hline Ahmadi et al. ${ }^{25}$ & MWCNT-engine oil & $\begin{array}{l}\text { Two-step method, flash point and heat transfer enhanced } 6.7 \text { and } 13.2 \% \text { for wt. } \%= \\
0.1 \text { respectively. }\end{array}$ \\
\hline Ding et al..$^{26}$ & $\begin{array}{l}\text { Diamond-Refrigerant/oil } \\
\text { R113+oil (VG68) }\end{array}$ & $\begin{array}{l}\text { wt. } \%=0-5 \text {, surfactant including SDS, CTAB were employed as dispersant. Enhance- } \\
\text { ment in pool boiling heat transfer coefficient up to } 63.4 \% \text {. }\end{array}$ \\
\hline Behabadi et al. ${ }^{27}$ & $\mathrm{R} 600 / \mathrm{CuO} / \mathrm{oil}$ & $\begin{array}{l}\text { For refrigerant/oil mixture heat transfer coefficient increases for (vapor quality }<0.6 \text { ). } \\
\text { For refrigerant/oil mixture heat transfer coefficient decreases for higher vapor quali- } \\
\text { ties. Adding } \mathrm{CuO} \text { nanoparticles improves the heat transfer coefficient up to } 63 \% \text {. }\end{array}$ \\
\hline
\end{tabular}


of $C$. militaris mycelium as reducing agents. The formation of AgNPs was first confirmed by the surface plasmon resonance illustrated in UV-visible spectrophotometer. X-ray diffraction analysis further confirmed that the AgNPs were composed of highly crystalline Ag. Transmission electron microscopy analysis revealed that most of the AgNPs were of spherical shape with mean diameter about $15 \mathrm{~nm}$. Although they synthesized a relatively pure $\mathrm{Ag}$ by a new method, they did not investigate the thermal performance of the Ag.

In another study, Benakashani et al. ${ }^{29}$ reported the synthesis of silver nanoparticles by reducing the silver ions present in the solution of silver nitrate with the cell free aqueous extract of Capparis spinosa leaves. Silver nanoparticles (AgNPs) were successfully synthesized using $C$. spinosa extract and the nature of the synthesized nanoparticles was analyzed by UV-Vis spectroscopy, transmission electron microscopy, $\mathrm{X}$-ray diffraction, and Fourier transform infrared spectroscopy. The antimicrobial effect of NPs produced with C. spinosa was studied using different pathogenic bacteria, such as Escherichia coli, Salmonella typhimurium, Staphylococcus aureus, and Bacillus cereus. Despite the antibacterial activity of Ag particles, they reported no information on its heat transfer application.

Salari et al. ${ }^{30}$ investigated a procedure for the synthesis of silver nanoparticles. In this research, silver nanoparticles (SNPs) were synthesized through bio-reduction of silver ions using the Spirogyra varians. The structure and morphology of SNPs were characterized by UV-visible spectroscopy, X-ray diffraction (XRD) pattern, scanning electron microscopy (SEM), and Fourier Transform Infra-Red (FTIR). These nanoparticles indicated an absorption peak at $430 \mathrm{~nm}$ in the UV-visible spectrum. The crystallite average size was estimated about $17.6 \mathrm{~nm}$ and SEM image confirmed synthesis of relatively uniform nanoparticles. The antibacterial effect of SNPs was also tested on several micro-organisms by measuring the inhibition zone. However, they did not consider the thermal application of the Ag particles.

In view of the aforementioned literature, in the present work, thermal performance of biologically produced Ag nanoparticles dispersed in coconut oil was investigated. Thermal conductivity and viscosity of $\mathrm{Ag} / \mathrm{coconut}$ oil nanofluids were experimentally measured and compared to available correlations. A new and accurate correlation is proposed for thermal conductivity of nanofluids. Thermal performance of nanofluids inside an annular heat exchanger in a convective boiling flow was also assessed and compared to commonly used car engine oil and the base oil.

\section{Materials and synthesis method}

For producing the nanoparticles, a modified version of biological method was utilized ${ }^{31,32}$. As a reducing agent, Camellia sinensis (green tea leaves) extract was used, as follows: Initially, about $15.54 \mathrm{~g}$ of tea leaves was washed and dried in a microwave-assisted oven. The dried leaves were ground and milled. The obtained powders were added to $100 \mathrm{~mL}$ deionized water in a clean flask. The mixture was boiled for $12 \mathrm{~min}$, quenched, screened, and filtered with micro-filter paper. Although $\mathrm{Yu}$ et al. suggested that the filtrate should be kept in $277 \mathrm{~K}$, we stored the filtrate at $288 \mathrm{~K}$ as the stock solution. Using TOC analyzer, total organic carbon (TOC) content of the tea extract was evaluated and analyzed (TOC-Dohrmann, Teledyne), which was approximately $19.07 \mathrm{~g} \mathrm{~L}^{-1}$. In the next step, $750 \mathrm{~mL}$ of silver nitrate $\left(10 \mathrm{mmol} \mathrm{L}^{-1}\right)$ (purchased from Merck Co. CAS\#7761-88-8) was added drop-wise into the $20 \mathrm{~mL}$ tea extract solution under sonication using Hielscher UP400S GmbH (210 W/24 kHz), and mechanically stirred at a speed of $400 \mathrm{rpm}$ for $100 \mathrm{~min}$ at 303-323 K. The Ag nanoparticles were concentrated and purified by centrifugal ultrafiltration, then rinsed and dried. Noticeably, the formation of Ag nanoparticles was indicated by the appearance of a signature smoky brown color of the solution, which is in good agreement with observations reported by $\mathrm{Yu}$ et al. ${ }^{32}$ Cocos nucifera oil (coconut oil) was also selected as the base fluid. According to the literature, it can be stated that coconut oil is an appropriate host fluid for dispersing the nanoparticles, because the thermal properties of coconut oil such as density, heat capacity and thermal conductivity are relatively higher than other traditional oils $^{33,34}$. Also, after dispersion of nanoparticles, no further stabilization process is required, which drastically reduces the toxicity of the nanofluid. In the present work, nanofluids were prepared at wt. $\%=$ $0.5,1$ and $1.5 \%$ of nanoparticles. The method of nanofluids preparation is shown schematically in Fig. 1.

The nanofluids were prepared at different weight concentrations of $0.5 \%, 1 \%$ and $1.5 \%$. Quality tests were perform to investigate the dispersion, size, and morphology of the nanoparticles inside the coolant. According to Scanning Electron Microscopic, (SEM) and Transmission Electron Microscopic images (TEM) shown in Figures 2(a-b), the nanoparticles are well-dispersed within the base fluid. Importantly, in terms of morphology and size, it can be seen that the particles are spherical and of the same size. As shown in Fig. 2(c), the Digital Light Scattering (DLS) test revealed that the nanoparticles mean size ranged approximately from 50 to $60 \mathrm{~nm}$. To check the purity and morphology, 
we examined the produced nanoparticles with XRD tests. XRD gives information on symmetry size and shape of the particles and purity of particles from peak positions. The XRD pattern presented in Fig. 2(d) shows the single-phase Ag nanoparticles with a monoclinic structure, indicating that there is no impurity other than Ag; however, a small peak due to the existence of $\mathrm{AgO}_{2}$ was also observed, which is negligible. More information can be found in literature ${ }^{33}$.

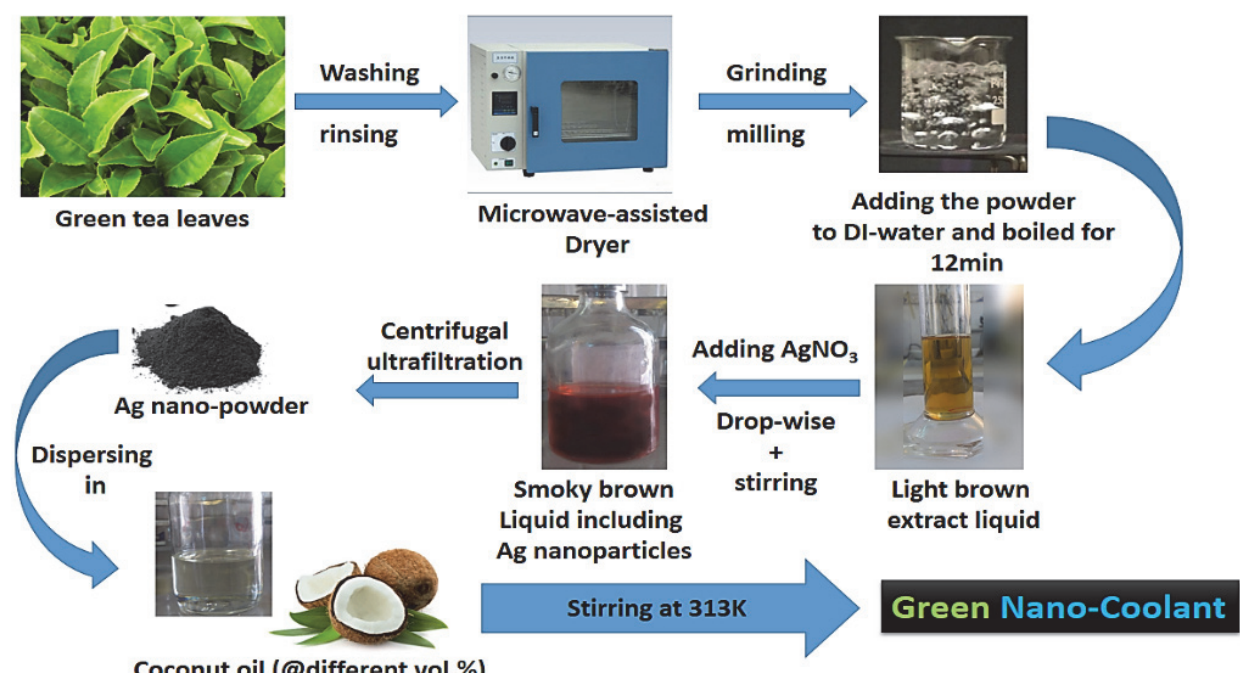

Fig. 1 - Schematic diagram of the preparation steps of Ag/coconut oil nanofluids

(a)

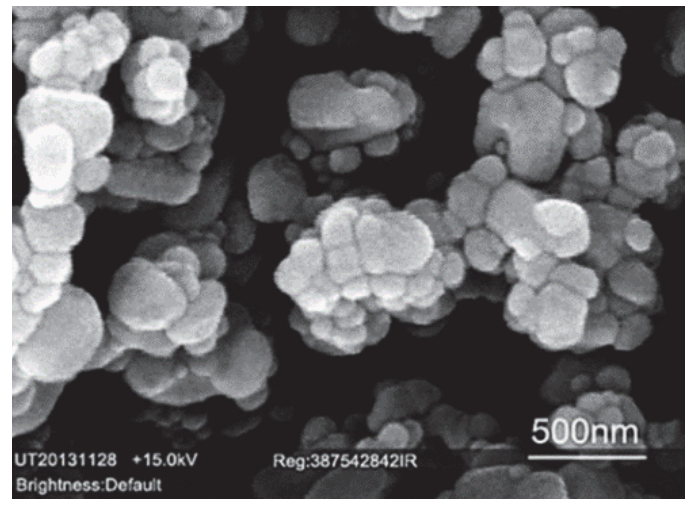

(c)

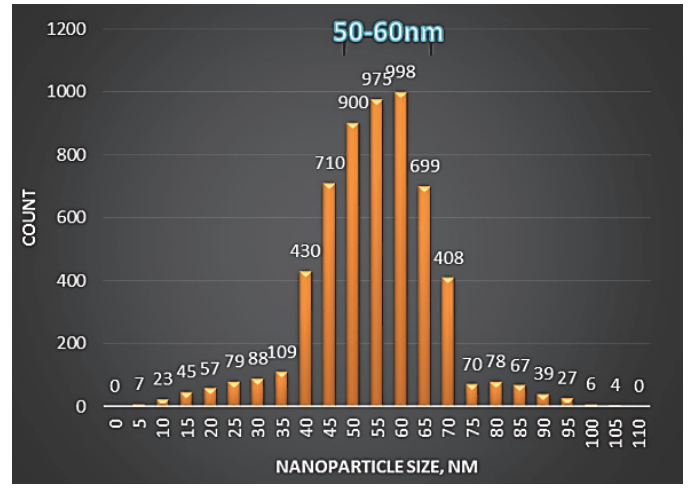

(b)

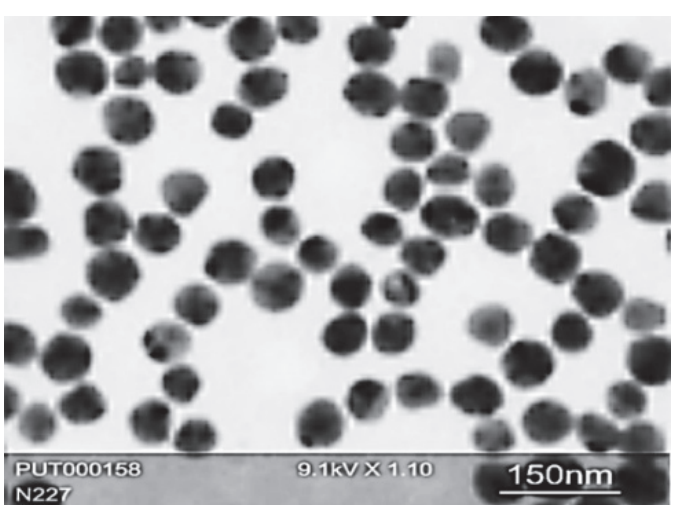

(d)

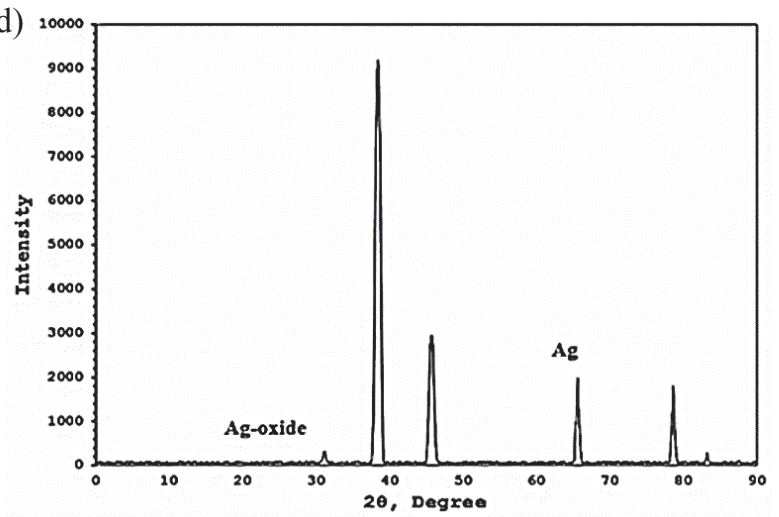

Fig. 2 - (a) Scanning electron microscopic image of Ag nanoparticles; (b)Transmission electron microscopic image of Ag nanoparticles dispersed in coconut oil; (c) Results of digital light scattering for determining the dominant size of particles; (d) Results of X-ray diffraction test for a biologically produced sample 


\section{Experimental}

For assessing the thermal performance of the $\mathrm{Ag} /$ coconut oil nanofluids, in high heat flux conditions, the flow boiling heat transfer coefficient of the nano-coolant was experimentally measured. For this purpose, a test rig, shown in Fig. 3, was utilized. The working fluid enters the loop from a main tank through the isolated pipes, and is continuously circulated by a centrifugal pump (DAB Co.). Since measuring the flow rate of fluid is very important in flow boiling; a Flownetix ultrasonic flow meter (uncertainty: $\pm 1 \%$ readings) was also installed in trajectory line of fluid to measure the flow rate with the least possible uncertainty. The fluid temperature was measured by two PT-100 thermometers (uncertainty: $\pm 0.1 \mathrm{~K}$ ) mounted on the pipes before and after the annular heat exchanger. The complete cylinder was made from stainless steel. Thermometer voltages, current, and voltage drop from the test heater were all measured and processed with a data acquisition system in conjunction with a PID temperature controller. The test section consisted of an electrically heated cylindrical DC bolt heater (manufactured by Cetal Co.) with a stainless steel surface, mounted concentrically within the surrounding pipe. The dimensions of the test section can be seen in Fig. 3. The length of the heated section was $140 \mathrm{~mm}$, meaning that only the first $140 \mathrm{~mm}$ of stainless steel is heated uniformly and radially by the heater. Therefore, the axial heat transfer profile through the rod could be ignored according to the insulation of both ends of the heater. The heat flux and wall temperature could be as high as $175 \mathrm{~kW} \mathrm{~m}^{-2}$ and $184{ }^{\circ} \mathrm{C}$, respectively. The local wall temperatures were measured with four stainless steel sheathed K-type thermocouples installed close to the heat transfer surface. The temperature drop between the thermocouples location and the heat transfer surface were calculated from:

$$
T_{w}=T_{t h}-\dot{q} \frac{s}{\lambda_{w}}
$$

The ratio between the distance of the thermometers from the surface and the thermal conductivity of the tube material $\left(s / \lambda_{v}\right)$ was determined for each K-type thermocouple (uncertainty: $\pm 0.1 \mathrm{~K}$ ) by calibration using Wilson plot technique ${ }^{35}$. The average temperature difference for each test section was the arithmetic average of the four thermometers readings around the circumference of the rod. The average of 10 voltage readings was used to determine the difference between the wall and bulk temperature for each thermometer. All the K-type thermocouples were thoroughly calibrated using a constant temperature water bath, and their accuracy was estimated at $\pm 0.3 \mathrm{~K}$. The local heat transfer coefficient $\alpha$ was then calculated from:

$$
\alpha=\frac{\dot{q}}{\left(T_{w}-T_{b}\right)_{\text {ave. }}}
$$

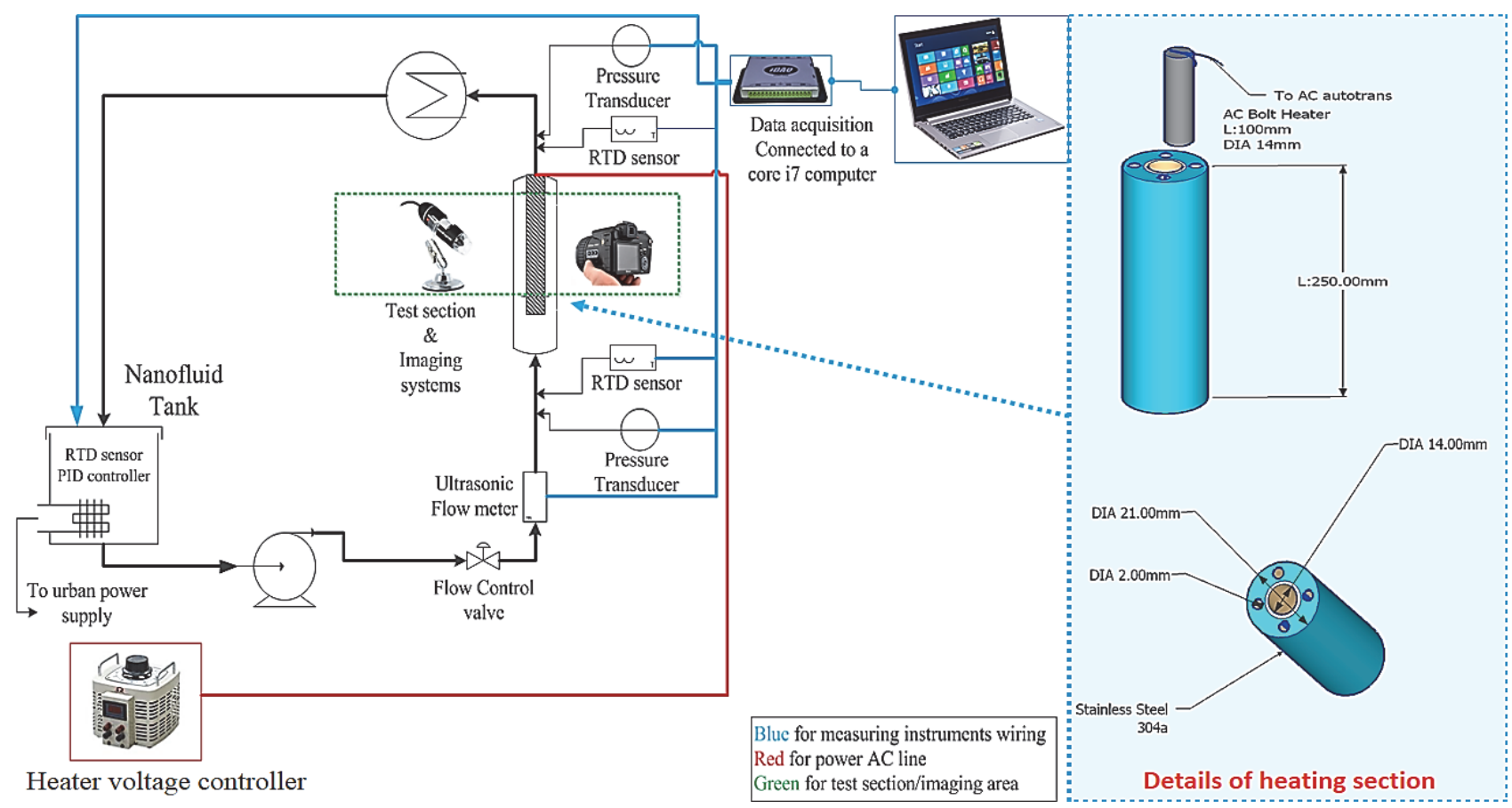

Fig. 3 - Scheme of the test rig for the assessment of thermal performance of nanofluids and details of annular test section 
To minimize the thermal contact resistance, high quality silicone paste was injected into the thermocouple wells. To avoid possible heat loss, the main tank circumferences were heavily insulated using industrial glass wool. To control the fluctuations due to the alternative current, a regular DC power supply was also employed to supply the needed voltage to the central heater. Likewise, to visualize the flow and boiling phenomenon and record the proper images, the annulus was made of Pyrex glass. Fig. 3 schematically represents the experimental test apparatus. To evaluate the uncertainty analysis, Kline-McKlintock method was used ${ }^{36}$. The major uncertainties in the measurement of the heat transfer coefficient can be related to the errors in the measurements of volume flow rate, hydraulic diameter, and all the temperatures. Therefore, the main uncertainty for the heat transfer coefficient as thermal performance index is $16.234 \%$. More information about uncertainty analysis can be found in our previous publication ${ }^{37}$.

\section{Results and discussion}

\section{Thermal properties}

\section{Thermal conductivity}

To measure the thermal conductivity of the prepared nanofluids, the KD2 pro Decagon instrument was utilized (uncertainty: $5 \%$ reading), and thermal conductivity of nanofluids at different temperatures was measured and compared to existing correlations. Noticeably, calibration tests were performed on DI-water to show the accuracy of the experimental device. The results were compared to those reported in literature, which showed that the calibration results were in excellent agreement with literature for DI-water.

The obtained results for the nanofluids were examined against the available correlations and it was found that the available correlations were unable to provide the reasonable values for thermal conductivity of nanofluids. Thus, a new correlation was proposed using regression analysis for estimating the thermal conductivity. Noticeably, for better understanding, an enhancement ratio was defined as:

Thermal conductivity Enhancement ratio $=\frac{k_{\text {nanofluid }}}{k_{\text {base fluid }}}$

Fig. 4 presents the dependence of enhancement ratio on temperature for different concentration of nanofluids.

According to Fig. 4, thermal conductivity of nanofluids at any concentration is significantly higher than that measured for the base oil. As can

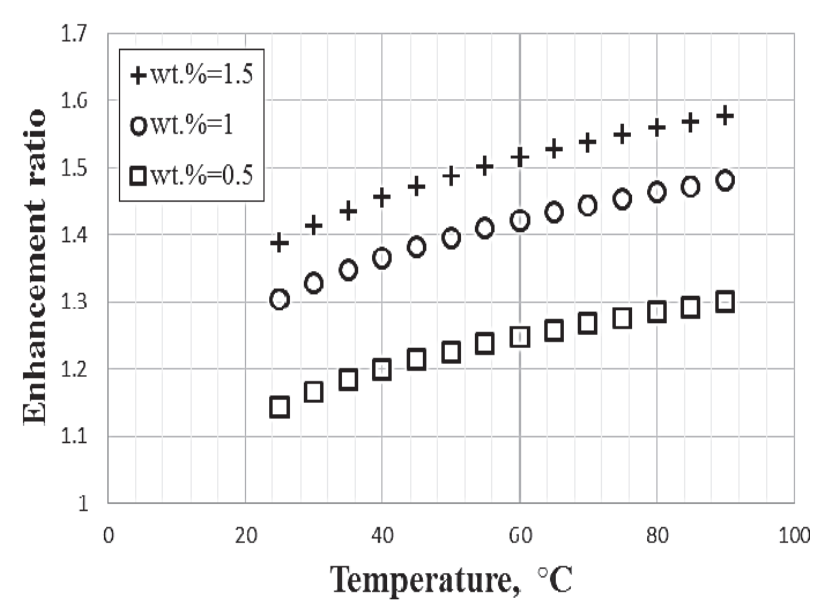

Fig. 4 - Dependence of thermal conductivity enhancement ratio on temperature for different concentrations of nanofluids

also be seen, with an increase in concentration of nanoparticles, the enhancement ratio increases. In addition, a slight increase in thermal conductivity due to an increase in temperature is seen. In fact, thermal conductivity of nanofluid is a strong function of concentration of nanoparticles and operating temperature. This is largely due to the enhancement in Brownian motion and internal thermal conductivity of $\mathrm{Ag}$, which is increased with an increase in concentration.

To correlate the experimental data, it was assumed that thermal conductivity is a function of temperature and volume fraction of nanoparticles dispersed in the base oil. Therefore, the dependency of thermal conductivity on temperature and volume fraction was separately considered. Thus, summation of the correlations will result in a simple, but accurate correlation for estimating the thermal conductivity of nanofluid, as:

$$
\frac{k_{n f}}{k_{b f}}=f(\varphi, T)=k_{0}+a \varphi+b T+c \varphi^{2}+d T^{2}
$$

Eq. 4 is a summation of the two following correlations. In a constant temperature, the influence of nanoparticles concentration on the thermal conductivity of the nanofluid can be obtained by Eq. 5:

$$
\frac{k_{n f}}{k_{b f}}=f(\varphi, T=c t e)=a \varphi+c \varphi^{2}
$$

$a, b$ are obtained using precise regression. In a constant concentration, influence of temperature on thermal conductivity can be shown by a second-order polynomial as:

$$
\frac{k_{n f}}{k_{b f}}=f(\varphi=c t e, T)=k_{0}+b T+d T^{2}
$$

Table 2 represents the numerical values of constants in regression. Note that our experimental criterion for concentration was the weight fraction, 
Table 2 - Numerical values of constants defined in Eq. (6)

\begin{tabular}{c|c|c|c|c|c|c|c}
\hline Constant & $a$ & $b$ & $c$ & $d$ & $k_{0}$ & $R^{2}$ & Standard error \\
\hline Numerical value & 58.6146 & 0.0052 & -1609.0286 & $-2.22 \mathrm{E}-5$ & 0.7688 & 0.99981 & $5.42 \%$ \\
\hline
\end{tabular}

while in the regression analysis, the weight fraction was converted to vol. \%.

Fig. 5 represents the results of comparison for available correlations in literature ${ }^{38}$ and the proposed correlation. As can be seen, the Maxwell equation and correlation suggested by Patel et al. overestimated the experimental data, while Xue et al., Yu-Choi and Hamilton-Crosser, all underestimated the experimental data.

\section{Viscosity}

Viscosity of oil is a key parameter, especially for nano-lubricants, in which the presence of particles may result in enhancement of viscosity and changes in the behavior of the oil. Viscosity can significantly influence pumping power and lubrication performance of oil for high-friction surfaces. In the present work, viscosity of nanofluid was measured at different temperatures and concentration of nanoparticles using Brookfield digital viscometer DV-E series (uncertainty: $0.1 \%$ of readings). The results showed that with an increase in nanoparticle concentration, the viscosity of the nanofluid significantly increases. Noticeably, at lower concentrations, a thin layer of nanoparticles is deposited on the surface and between layers of oil, which increases the interlayer movement of lubricants and also on the surface, but at higher concentrations, the nanoparticles form clusters and aggregations, which increase the roughness. These all result in enhancement of nanofluid viscosity. According to the ob-

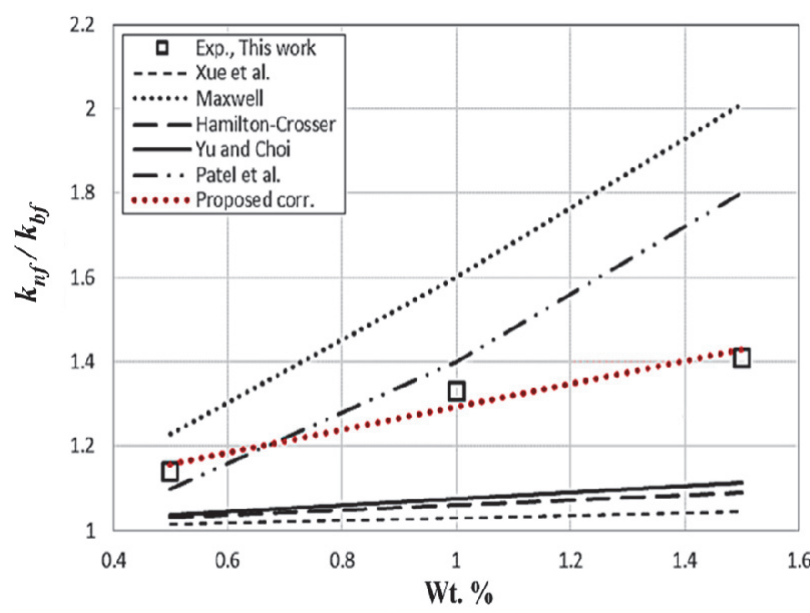

Fig. 5 - Comparison between thermal conductivity enhancement ratio obtained by the correlations against the experimental data; temperature $=25{ }^{\circ} \mathrm{C}$ tained results, the viscosity decreases with an increase in temperature, while by increasing the nanoparticles concentration, the viscosity significantly increases. Similar to thermal conductivity, for viscosity, the enhancement ratio is defined as:

$$
\text { Enhancement ratio }=\frac{\mu_{\text {nanofluid }}}{\mu_{\text {base fluid }}}
$$

Fig. 6 represents the dependence of viscosity enhancement ratio on temperature for different nanoparticles concentrations. As can be seen, deterioration of viscosity with temperature is obvious, which is in accordance with earlier works ${ }^{2,21}$. Noticeably, viscosity of nanofluids is relatively higher than that measured for the base fluid.

It can also be stated that addition of nanoparticles leads to an increase in viscosity, which is not appreciable for some applications, such as low-temperature lubrications, while for heavy-oil applications, such as high heat-temperature conditions in engines, using the nano-lubricants can enhance the thermal properties and viscosity in comparison with base oils ${ }^{38}$.

\section{Boiling thermal performance}

Conveniently, the convective boiling heat transfer coefficient was considered as thermal performance index for high heat flux conditions. Boiling heat transfer comprises different heat transfer mechanisms, namely forced convection heat transfer and nucleate boiling regimes.

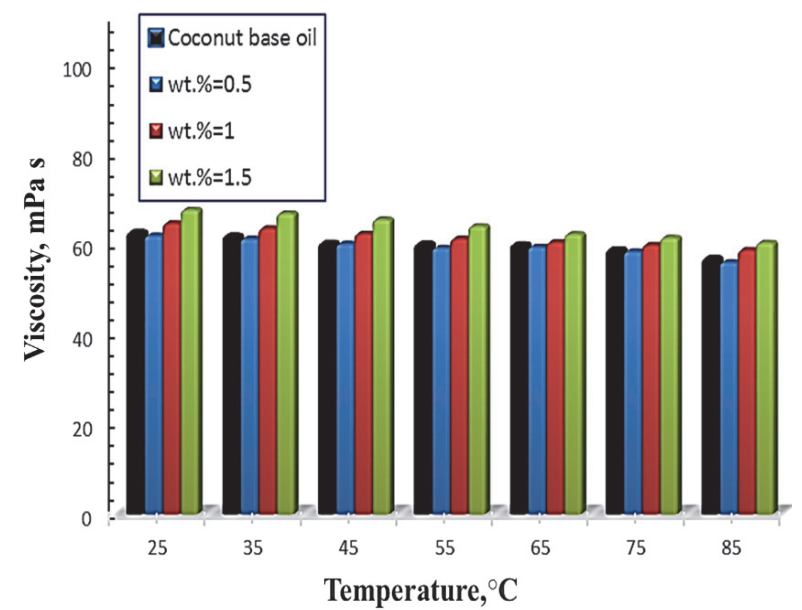

Fig. 6 - Experimental viscosity of nanofluid at different temperatures for different concentrations of nanofluids 
Table 3 -Operating conditions related to flow boiling experiments

\begin{tabular}{l|l|l}
\hline Operating parameter & \multicolumn{1}{|c|}{ Value } & \multicolumn{1}{c}{ SI unit } \\
\hline Heat flux & $5-170$ & $\mathrm{~kW} \mathrm{~m}^{-2}$ \\
Mass flux & $80-1200$ & $\mathrm{~kg} \mathrm{~m}^{-2} \mathrm{~s}^{-1}$ \\
Reynolds number & $900-15503$ & - \\
Concentration & $0.5,1,1.5$ & wt. $\%$ \\
Surface roughness & 0.4 (clean) - & $\mu \mathrm{m}$ \\
Sub-cooling & 0.52 (deposited) & \\
\hline
\end{tabular}

Table 3 shows the experimental conditions used for the boiling experiments. As can be seen, Reynolds number varies from 900 (laminar regime) to 15503 (turbulent regime) to assess the performance of nanofluids at different flow regimes. Also, heat flux is varied from $7 \mathrm{~kW} \mathrm{~m}^{-2}$ (forced convective) up to $170 \mathrm{~kW} \mathrm{~m}^{-2}$ (nucleate boiling heat transfer regime).

According to the experimental results, in the nucleate boiling region, higher heat transfer coefficient is seen in comparison with forced convection region. This is largely due to the bubble formation on the heating surface, which intensifies the local movements of fluid. Bubble interactions also intensify the Brownian motion of particles. Overall, Ag/ coconut nanofluid presents reasonable cooling performance at high heat flux and two-phase systems.

Fig. 7 shows the dependence of heat transfer coefficient on Reynolds number for different concentrations of nanofluids and at different heat fluxes belonging to forced convection and nucleate boiling regions. Noticeably, with an increase in concentration of $\mathrm{Ag}$ nanoparticles into the base oil, higher heat transfer coefficient is seen for both heat transfer regions. Moreover, an increase in fluid flow rate results in enhancement of heat transfer coefficient. However, the value of heat transfer coefficient for laminar region is relatively lower than that obtained for the nucleate boiling region. More importantly, with an increase in concentration of nanofluid, the boiling heat transfer coefficient increases. This is mainly due to the presence of nanoparticles which can enhance the thermal conductivity of nanofluid. This results in enhancement of thermal performance of nanofluid.

Fig. 8 presents the heat transfer coefficient of $\mathrm{Ag} /$ coconut oil nanofluids and base oil (coconut oil) in comparison with car engine oil $(20 \mathrm{~W}-50$ provided by Castrol GTX). Castrol GTX was selected as it is widely used in the automotive industry, however, other oils can also be compared. As can be seen, for all the heat fluxes, the heat transfer coefficient of $\mathrm{Ag} /$ coconut oil nanofluid is greater than that of the base fluid as well as that of Castrol oil. In fact, the addition of Ag nanoparticles improves the thermal performance of coconut base oil. On the other hand, the presence of nanoparticles influences the thermal conductivity, Brownian motion, and viscosity of coconut oil. Therefore, better thermal performance is reported for the nanofluid in comparison with engine oil and coconut oil.

It is worth noting that fouling formation is a major drawback in the use of nanofluids in cooling systems. In this work, fouling formation of $\mathrm{Ag}$ particles on the heating surface of an annular heat exchanger was constantly monitored using IUP500X digital microscope. The results were compared to alumina and copper aqueous nanofluids to understand the fouling behavior of a biologically produced nanofluid. In our earlier publications, fouling of different nanoparticles on the heating surface was investigated ${ }^{28,29,34}$.

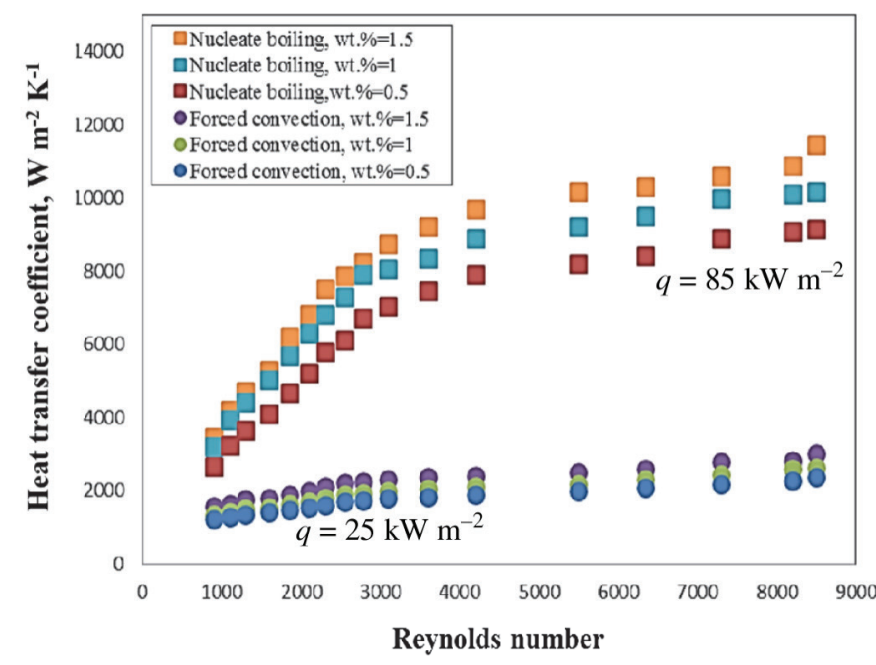

Fig. 7 - Comparison between heat transfer coefficient at different heat transfer regions for different weight concentrations of Ag nanoparticles

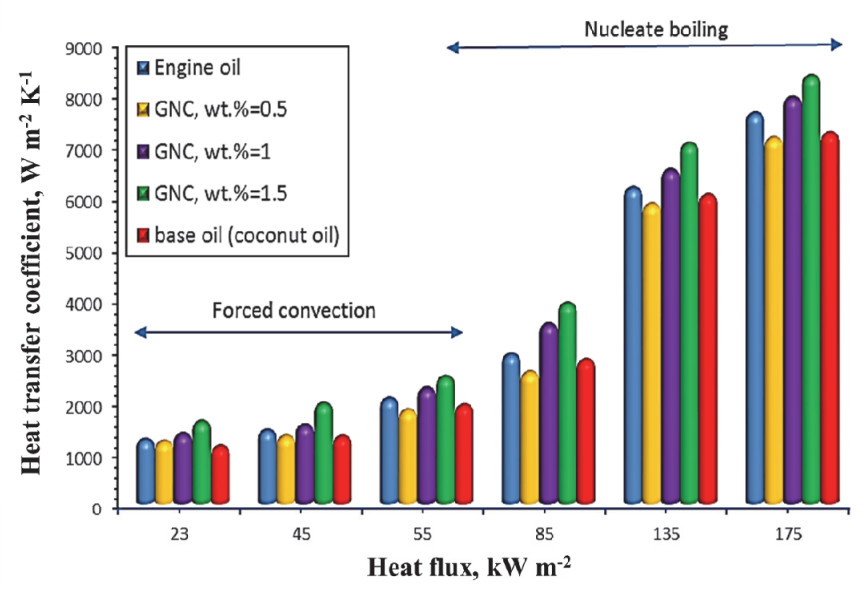

Fig. 8 -Comparison between thermal performance of nanofluid, base oil, and car engine oil 


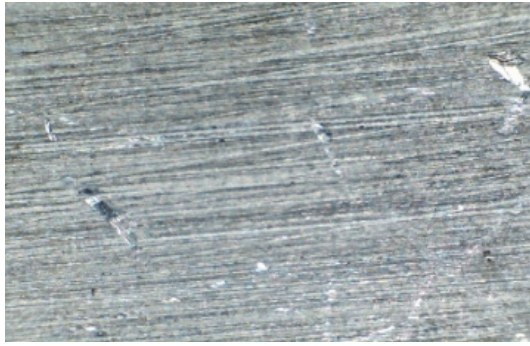

Ag/coconut oil

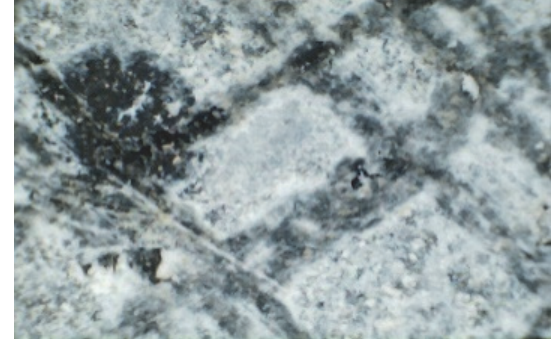

Alumina/DI-water

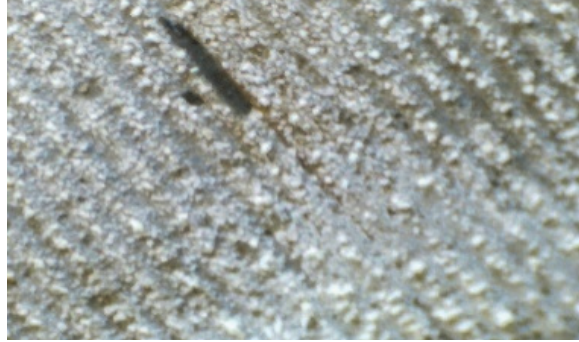

$\mathrm{CuO} / \mathrm{DI}-$ water

Fig. 9 - Morphology of heating surface during boiling of silver-coconut oil nanofluids in comparison with alumina-water and copper-water nanofluids. Operating time: 1000 min under boiling conditions; heat flux: $85 \mathrm{~kW} \mathrm{~m}$; mass flux: $800 \mathrm{~kg} \mathrm{~m}^{-2} \mathrm{~s}^{-1}$.

For $\mathrm{Ag} /$ coconut oil nanofluid, it was found that nanoparticles exhibited different behavior, such that the heat transfer coefficient remained constant over time, and fouling of Ag particles had not changed the surface characteristics. More importantly, it was found that nanoparticles had not formed clusters and aggregations on the surface. In fact, in the boiling micro-layer, the rate of evaporation for coconut oil was lower than that of other base fluids such as ethylene glycol or DI-water. As a result, particulate behavior of nanoparticles remained stable and sedimentation of particles on the surface significantly decreased over time. Moreover, a polarized layer of nanoparticles around the heating surface had not formed, which led to decreased thermal resistance (fouling resistance).

Fig. 9 presents the morphology of the heating surface after working hours of about $1000 \mathrm{~min}$. For $\mathrm{Ag} /$ coconut oil nanofluid, a very thin layer of deposition is visible, while for other nanofluids, such as alumina or copper oxide aqueous nanofluids, significant thickness of deposition can clearly be seen. This thickness not only enhances the thermal resistance on the surface but also changes the surface characteristics, which decreases the thermal properties of the surface. Also, rate of evaporation of base fluid is another important parameter, which influences the rate of deposition of particles ${ }^{39-48}$ and needs further investigation, which is out of scope of this articles. Also, deposition of Ag nanoparticles may have significant influences on cancer treatment and drug delivery systems, which needs to be investigated $^{52-56}$.

\section{Conclusions}

In this work, thermal performance of biologically produced Ag nanoparticles dispersed in coconut oil was investigated. The thermal conductivity and viscosity of this nanofluid was experimentally measured and correlated. Also, the following conclusions were drawn:
- The results indicated that $\mathrm{Ag} /$ coconut oil nanofluids exhibit reasonable thermal conductivity due to the presence of Ag nanoparticles. An average enhancement ratio of $60 \%$ was reported for wt. $\%$ $=1.5$. Also, viscosity of $\mathrm{Ag} /$ coconut oil nanofluids was enhanced due to the $\mathrm{Ag}$ nanoparticles.

- The results suggested that thermal conductivity and viscosity of $\mathrm{Ag} /$ coconut oil nanofluids are functions of temperature and nanoparticles concentration. With an increase in temperature the thermal conductivity slightly increases, while viscosity of nanofluids decreases. An increase in concentration of particles enhances the viscosity and thermal conductivity.

- In terms of thermal performance, the results suggested that the boiling heat transfer coefficient of $\mathrm{Ag} /$ coconut oil nanofluids was relatively higher than that of the base fluid and with an increase in nanoparticles concentration, the boiling heat transfer coefficient had also increased.

Overall, the biologically produced Ag/coconut oil is a promising option for cooling systems working in high heat flux conditions, and it can also be used for lubricating purposes due to its enhanced viscosity. Fouling formation for this nanofluid is negligible in comparison with other tested nanofluids, including alumina and copper oxide aqueous nanofluids.

\section{ACKNOWLEDGEMENT}

The authors wish to dedicate this article to Imam Mahdi and thank the Semnan University for their financial support.

\section{Nomenclatures:}

a - Constant

$b \quad-$ Constant

c - Constant

d - Constant 
$k-$ Thermal conductivity, $\mathrm{W} \mathrm{m}^{-1} \mathrm{~K}^{-1}$

$k_{0}-$ Constant

$T$ - Temperature, $\mathrm{C}$ or $\mathrm{K}$

$\dot{q} \quad-$ Heat flux, $\mathrm{kW} \mathrm{m}^{-2}$

$s \quad-$ Thickness of heater, $\mathrm{m}$

\section{Greek letters}

$\lambda \quad-$ Thermal conductivity of heater, $\mathrm{W} \mathrm{m}^{-1} \mathrm{~K}^{-1}$

$\alpha \quad$ - Heat transfer coefficient, $\mathrm{W} \mathrm{m}^{-2} \mathrm{~K}^{-1}$

$\mu \quad-$ Viscosity, $\mathrm{N} \mathrm{m}^{-1}$

$\phi \quad-$ Volumetric concentration

\section{Sub-scripts}

$$
\begin{array}{ll}
\text { bf } & - \text { base fluid } \\
\text { nf } & - \text { nanofluids } \\
\text { w } & - \text { wall (heater) }
\end{array}
$$

\section{References}

1. Sundar, L. S., Venkata Ramana, E., Singh, M. K., Sousa, A. M., Thermal conductivity and viscosity of stabilized ethylene glycol and water mixture $\mathrm{Al}_{2} \mathrm{O}_{3}$ nanofluids for heat transfer applications: An experimental study, Int. Communications Heat Mass Trans. 56 (2014) 86.

doi: https://doi.org/10.1016/j.icheatmasstransfer.2014.06.009

2. Nabeel Rashin, M., Hemalatha, J., Synthesis and viscosity studies of novel ecofriendly $\mathrm{ZnO}$-coconut oil nanofluid, Exp. Thermal Fluid Sci. 51 (2013) 312.

doi: https://doi.org/10.1016/j.expthermflusci.2013.08.014

3. Choi, S. U.S., Enhancing thermal conductivity of fluids with nanoparticle, ASME FED 231 (1995) 99.

4. Pak, B. C., Cho, Y. I., Hydrodynamic and heat transfer study of dispersed fluids with submicron metallic oxide particles, Exp. Heat Trans. 11 (1998) 151.

doi: https://doi.org/10.1080/08916159808946559

5. Xuan, Y. M., Li, Q., Investigation on convective heat transfer and flow features of nanofluids, ASME J. Heat Trans. 125 (2003) 151. doi: https://doi.org/10.1115/1.1532008

6. He, Y., Jin, Y., Chen, H., Ding, Y., Cang, D., Lu H., Heat transfer and flow behavior of aqueous suspensions of $\mathrm{TiO}_{2}$ nanoparticles (nanofluids) flowing upward through a vertical pipe, Int. J. Heat Mass Trans. 50 (2007) 2272. doi: https://doi.org/10.1016/j.ijheatmasstransfer.2006.10.024

7. Sundar, L., Sharma, K. V., Ramanathan, S., Experimental investigation of heat transfer enhancements with $\mathrm{Al}_{2} \mathrm{O}_{3}$ nanofluid and twisted tape insert in a circular tube, Int. J. Nanotechnol. Appl. 1 (2007) 21.

8. Kulkarni, D. P., Das, D. K., Vajjha, R. S., Application of nanofluids in heating buildings and reducing pollution, Appl. Energy 86 (2009) 2566. doi: https://doi.org/10.1016/j.apenergy.2009.03.021

9. Sarafraz, M. M., Hormozi, F., Nucleate pool boiling heat transfer characteristics of dilute $\mathrm{Al}_{2} \mathrm{O}_{3}$-ethyleneglycol nanofluids, Int. Communications Heat Mass Trans. 58 (2014) 96.

doi: https://doi.org/10.1016/j.icheatmasstransfer.2014.08.028
10. Lee, J., Jeong, Y. H., CHF enhancement in flow boiling system with TSP and boric acid solutions under atmospheric pressure, Nucl. Eng. Des. 240 (2010) 3594. doi: https://doi.org/10.1016/j.nucengdes.2010.05.027

11. Celata, G. P., Mishima, K., Zummo, G., Critical heat flux prediction for saturated flow boiling of water in vertical tubes, Int. J. Heat Mass Transfer 44 (2001) 4323. doi: https://doi.org/10.1016/S0017-9310(01)00072-2

12. Henderson, K., Park, Y. G., Liu, L., Jacobi, A. M., Flow-boiling heat transfer of R-134a based nanofluids in a horizontal tube, Int. J. Heat Mass Trans. 5 (2010) 944. doi: https://doi.org/10.1016/j.ijheatmasstransfer.2009.11.026

13. Fan, L.-W., Li, J.-Q., Li, D.-Y., Zhang, L., Yu Z., Cen, K., The effect of concentration on transient pool boiling heat transfer of graphene-based aqueous nanofluids, Int. J. Thermal Sci. 91 (2015) 83. doi: https://doi.org/10.1016/j.ijthermalsci.2015.01.009

14. Sarafraz, M. M., Hormozi, F., Nucleate pool boiling heat transfer characteristics of dilute $\mathrm{Al}_{2} \mathrm{O}_{3}$-ethyleneglycol nanofluids, Int. Commun. Heat Mass Trans. 58 (2014) 96. doi: https://doi.org/10.1016/j.icheatmasstransfer.2014.08.028

15. Sarafraz, M. M., Hormozi, F., Pool boiling heat transfer to dilute copper oxide aqueous nanofluids, Int. J. Thermal Sci. 90 (2015) 224. doi: https://doi.org/10.1016/j.ijthermalsci.2014.12.014

16. Sarafraz, M. M., Hormozi, F., Scale formation and subcooled flow boiling heat transfer of $\mathrm{CuO}$-water nanofluid inside the vertical annulus 52 (2014) 205.

17. Tang, X., Zhao, Y. H., Diao, Y., Experimental investigation of the nucleate pool boiling heat transfer characteristics of $\delta-\mathrm{Al}_{2} \mathrm{O}_{3}-\mathrm{R} 141 \mathrm{~b}$ nanofluids on a horizontal plate, Exp. Thermal Fluid Sci. 52 (2014) 88. doi: https://doi.org/10.1016/j.expthermflusci.2013.08.025

18. Raveshi, M. R., Keshavarz, A., Mojarrad, M. S., Amiri, S., Experimental investigation of pool boiling heat transfer enhancement of alumina-water-ethylene glycol nanofluids, Exp. Thermal Fluid Sci. 44 (2013) 805. doi: https://doi.org/10.1016/j.expthermflusci.2012.09.025

19. Akhavan-Behabadi, M. A., Hekmatipour, F., Mirhabibi, S. $M$., Sajadi, B., An empirical study on heat transfer and pressure drop properties of heat transfer oil-copper oxide nanofluid in micro-fin tubes, Int. Communications Heat Mass Trans. 57 (2014) 150. doi: https://doi.org/10.1016/j.icheatmasstransfer.2014.07.025

20. Li, H. J., Zan, C., Wang, F., Yang, Q., Shi, L., Temperature dependence of the stability and thermal conductivity of an oil-based nanofluid, Thermochimica Acta 579 (2014) 27. doi: https://doi.org/10.1016/j.tca.2014.01.012

21. Nabeel Rashin, M., Hemalatha, J., Viscosity studies on novel copper oxide-coconut oil nanofluid, Experimental Thermal and Fluid Science 48 (2013) 67. doi: https://doi.org/10.1016/j.expthermflusci.2013.02.009

22. Saeedinia, M., Akhavan-Behabadi, M. A., Razi, P., Thermal and rheological characteristics of $\mathrm{CuO}-$ Base oil nanofluid flow inside a circular tube, Int. Communications Heat Mass Trans. 39 (2012) 152. doi: https://doi.org/10.1016/j.icheatmasstransfer.2011.08.001

23. Chen, L., Xie, H., Silicon oil based multiwalled carbon nanotubes nanofluid with optimized thermal conductivity enhancement, Colloids and Surfaces A: Physicochemical and Engineering Aspects 352 (2009) 136. doi: https://doi.org/10.1016/j.colsurfa.2009.10.015

24. Ashtiani, D., Akhavan-Behabadi, M. A., Fakoor Pakdaman, $M$., An experimental investigation on heat transfer characteristics of multi-walled CNT-heat transfer oil nanofluid flow inside flattened tubes under uniform wall temperature 
condition, Int. Communications Heat Mass Trans. 39 (2012) 1404.

25. Ettefaghi, E., Ahmadi, H., Rashidi, A., Nouralishahi, A., Mohtasebi, S. S., Preparation and thermal properties of oilbased nanofluid from multi-walled carbon nanotubes and engine oil as nano-lubricant, Int. Communications Heat Mass Trans. 46 (2013) 142.

doi: https://doi.org/10.1016/j.icheatmasstransfer.2013.05.003

26. Hu, H., Peng, H., Ding, G., Nucleate pool boiling heat transfer characteristics of refrigerant/nanolubricant mixture with surfactant, Int. J. Refrigeration 36 (2013) 1045. doi: https://doi.org/10.1016/j.ijrefrig.2012.12.015

27. Akhavan-Behabadi, M. A., Nasr, M., Baqeri, S., Experimental investigation of flow boiling heat transfer of R-600a/oil/ $\mathrm{CuO}$ in a plain horizontal tube, Exp. Thermal Fluid Sci. 58 (2014) 105. doi: https://doi.org/10.1016/j.expthermflusci.2014.06.013

28. Wang, L., Liu, C.-C., Wang, Y.-Y., Xu, H., Su, H., Cheng, X., Antibacterial activities of the novel silver nanoparticles biosynthesized using Cordyceps militaris extract, Current Applied Physics 16 (2016) 969. doi: https://doi.org/10.1016/j.cap.2016.05.025

29. Benakashani, F., Allafchian, A., Jalali, S., Biosynthesis of silver nanoparticles using Capparis spinosa L. leaf extract and their antibacterial activity, Karbala International Journal of Modern Science (2016)

doi: https://doi.org/10.1016/j.kijoms.2016.08.004

30. Salari, Z., Danafar, F., Dabaghi, S., Ataei, S. A., Sustainable synthesis of silver nanoparticles using macroalgae Spirogyra varians and analysis of their antibacterial activity, J. Saudi Chemical Soc. 20 (2014) 459. doi: https://doi.org/10.1016/j.jscs.2014.10.004

31. Sarafraz, M. M., Hormozi, F., Peyghambarzadeh, S. M., Thermal performance and efficiency of a thermosyphon heat pipe working with a biologically ecofriendly nanofluid, Int. Communications Heat Mass Trans. 57 (2014) 297. doi: https://doi.org/10.1016/j.icheatmasstransfer.2014.08.020

32. Sun, Q., Cai, X., Li, J., Zheng, M., Chen, Z., Yu, C., Green synthesis of silver nanoparticles using tea leaf extract and evaluation of their stability and antibacterial activity, Colloids and Surfaces A: Physicochem. Eng. Aspects 444 (2014) 226.

doi: https://doi.org/10.1016/j.colsurfa.2013.12.065

33. Sarafraz, M. M., Hormozi, F., Kamalgharibi, M., Sedimentation and convective boiling heat transfer of $\mathrm{CuO}$-water/ ethylene glycol nanofluids, Heat Mass Trans. 50 (2014) 1237.

doi: https://doi.org/10.1007/s00231-014-1336-y

34. Sarafraz, M. M., Hormozi, F., Convective boiling and particulate fouling of stabilized $\mathrm{CuO}$-ethylene glycol nanofluids inside the annular heat exchanger, Int. Communications Heat Mass Trans. 53 (2014) 116. doi: https://doi.org/10.1016/j.icheatmasstransfer.2014.02.019

35. Seara, J. F., Uhia, F. J., Sieres, J., Laboratory practices with the Wilson plot method, Exp. Heat Transfer 20 (2007) 123. doi: https://doi.org/10.1080/08916150601091415

36. Kline, S. J., McClintock, F. A., Describing uncertainties in single-sample experiments, Mech. Eng. 75 (1953) 3.

37. Nikkhah, V., Sarafraz, M. M., Hormozi, F., Peyghambarzadeh, S. M., Particulate fouling of $\mathrm{CuO}-$ water nanofluid at isothermal diffusive condition inside the conventional heat exchanger-experimental and modeling, Exp. Thermal Fluid Sci. 60 (2015) 83. doi: https://doi.org/10.1016/j.expthermflusci.2014.08.009
38. Dalkilic, A. S., Kayac, N., Celen, A., Tabatabaei, M., Yıldız, O., Daungthongsuk, W., Wongwises, S., Forced Convective Heat Transfer of Nanofluids - A Review of the Recent Literature, Current Nanoscience 1 (2012) 949 doi: https://doi.org/10.2174/157341312803989006

39. Sarafraz, M. M., Peyghambarzadeh, S. M., Alavi Fazel, S. $A$., Experimental studies on nucleate pool boiling heat transfer to ethanol/MEG/DEG ternary mixture as a new coolant, Chemical Ind. Chem. Eng. Q. 18 (2012) 577. doi: https://doi.org/10.2298/CICEQ111116033S

40. Sarafraz, M. M., Arya, A., Hormozi, F., Nikkhah, V., On the convective thermal performance of a CPU cooler working with liquid gallium and $\mathrm{CuO} /$ water nanofluid: A comparative study, Applied Thermal Eng. 112 (2017) 1373. doi: https://dx.doi.org/10.1016/j.applthermaleng.2016.10.196

41. Salari, E., Peyghambarzadeh, M., Sarafraz, M. M., Hormozi, F., Boiling heat transfer of alumina nano-fluids: role of nanoparticle deposition on the boiling heat transfer coefficient, Periodica Polytechnica Chemical Engineering 60 (2016) 252. doi: https://dx.doi.org/10.3311/PPch.9324

42. Sarafraz, M. M., Peyghambarzadeh, S. M., Alavi Fazel, S. $A$., Enhancement of the pool boiling heat transfer coefficient using the gas injection into the water, Polish Journal of Chemical Technology 14 (2012) 100. doi: http://dx.doi.org/10.2478/v10026-012-0110-5

43. Sarafraz, M. M., Peyghambarzadeh, S. M., Hormozi, F., Vaeli, $N$., Upward flow boiling to di-water and $\mathrm{CuO}$ nanofluids inside the concentric annuli, J. Applied Fluid Mechanics 8 (2015) 651.

44. Kamalgharibi, M., Hormozi, F., Zamzamian, S. A. H, Sarafra, z M. M., Experimental studies on the stability of $\mathrm{CuO}$ nanoparticles dispersed in different base fluids: influence of stirring, sonication and surface active agents, Heat and Mass Transfer 52 (2016) 55 doi: http://dx.doi.org/10.1007/s00231-015-1618-z

45. Salari, E., Peyghambarzadeh, S. M., Sarafraz, M. M., Hormozi, F., Boiling thermal performance of $\mathrm{TiO}_{2}$ aqueous nanofluids as a coolant on a disc copper block, Periodica Polytechnica, Chemical Engineering 60 (2016) 106. doi: http://dx.doi.org/10.3311/PPch.8262

46. Sarafraz, M. M., Hormozi, F., Nikkhah, V., Thermal performance of a counter-current double pipe heat exchanger working with $\mathrm{COOH}-\mathrm{CNT} /$ water nanofluids, Exp. Thermal Fluid Sci. 78 (2016) 41. http://dx.doi.org/10.1016/j.expthermflusci.2016.05.014

47. Sarafraz, M. M., Hormozi, F., Forced convective and nucleate flow boiling heat transfer to alumnia nanofluids, Periodica Polytechnica, Chemical Engineering 58 (2014) 37. doi: http://dx.doi.org/10.3311/PPch.2206

48. Sarafraz, M. M., Kiani, T., Hormozi, F., Critical heat flux and pool boiling heat transfer analysis of synthesized zirconia aqueous nano-fluids, Int. Communications Heat Mass Trans. 70 (2016) 75. http://dx.doi.org/10.1016/j.icheatmasstransfer.2015.12.008

49. Sarafraz, M. M., Experimental investigation on pool boiling heat transfer to formic acid, propanol and 2-butanol pure liquids under the atmospheric pressure, J. Applied Fluid Mechanics 6 (2013) 73.

50. Sarafraz, M. M., Nucleate pool boiling of aqueous solution of citric acid on a smoothed horizontal cylinder, Heat and Mass Transfer 48 (2012) 611. doi: http://dx.doi.org/10.1007/s00231-016-1823-4

51. Sarafraz, M. M. Peyghambarzadeh, S. M., Alavifazel, S. A., Enhancement of nucleate pool boiling heat transfer to dilute binary mixtures using endothermic chemical reactions 
around the smoothed horizontal cylinder, Heat Mass Trans. 48 (2012) 1755.

doi: http://dx.doi.org/10.1007/s00231-012-1019-5

52. Aryanpour, N., Mansouri-Torshizi, H., Nakhjavan, M., Shirazi, F. H., Cytotoxicity of diimine palladium(II) complexes of alkyldithiocarbamate derivatives on human lung, ovary and liver cells, Iranian J. Pharmaceutical Research 11 (2012) 689.

53. Nakhjavani, M., Zarghi, A., Shirazi, F. H., Cytotoxicity of selected novel chalcone derivatives on human breast, lung and hepatic carcinoma cell lines, Iranian J. Pharmaceutical Research 13 (2014) 953.
54. Jamali, B., Nakhjavani, M., Hosseinzadeh, L., Amidi, S., Nikounezhad, N., Shirazi, H., Intracellular GSH alterations and its relationship to level of resistance following exposure to cisplatin in cancer cells, Iranian Journal of Pharmaceutical Research 14 (2015) 513.

55. Nakhjavani, M., Vatanpour, H., Shahriari, F., Mohamadzadehasl, B., Lifesaving effect of lidocaine on Odontobuthos Doriae scorpion envenomation in mice, American J. PharmTech Research 6 (2016) 179.

56. Nikounezhad, N., Nakhjavani, M., Shirazi, F. H., Generation of cisplatin-resistant ovarian cancer cell lines, Iranian J. Pharmaceutical Sci. 12 (2016) 11 